Адрес статьи: pnojournal.wordpress.com/archive18/18-05/

Дата публикации: 1.11.2018

№ 5 (35). С. 82-93.

УДК 372.8

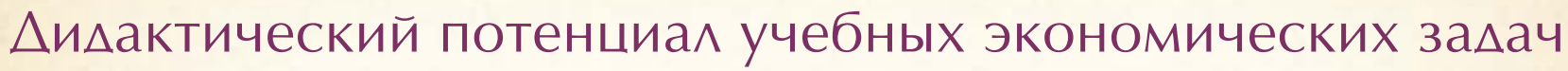 в условиях компетентностной парадигмы
}

В үсловиях компетентностной парадигмы в образовательной и профессиональной сфере проявляющейся в подчинении совокупности теоретических знаний бо́льшему объему конкретных умений и владению навыками выполнять профессиональные трудовые действия, для формирования и оценки уровня развития этих интегрированных элементов компетенций необходимо эффективное педагогическое средство. Наиболее доступным, а в отдельных случаях и единственным приемом, является решение учебных практико-ориентированных задач.

Цель статьи - обсуждение направлений, условий и практических примеров реализации дидактического потенциала экономических задач в образовательной и профессиональной сфере.

Методологической базой работы явились концепции компетентностного подхода; принципы системного, когнитивного, личностнодеятельностного подхода в обучении. В работе обобщены принципы отбора содержания пособий по решению экономических задач для студентов. Дан анализ текстовых задач с экономическим содержанием профильного уровня ЕГэ по математике. Учтен личный педагогический опыт составления и решения задач со студентами.

В работе обозначены основные методические и организационные проблемы реализации дидактических возможностей экономических задач на разных этапах «жизненного цикла» компетенций.

Показано, что неоспоримым преимуществом задач экономического типа является их способность формировать не только профессиональную когнитивную и операционально-технологическую составляющие, но и мотивационный, социальный и поведенческий элементы компетентностной модели выпускника и личности.

Резюмируется, что для реализации дидактического потенциала экономических задач должны целей, обусловленных уровнем образования. Обозначена необходимость повышения роли оценочной функции экономической задачи на этапах входного и итогового контроля по ступеням или этапам обучения, на междисциплинарном уровне, в профессиональной сфере. Примеры, иллюстрирующие отдельные положения статьи, могут служить ориентиром при составлении практикумов по решению задач и фондов оценочных средств.

Ключевые слова: компетентностная парадигма, учебная экономическая задача, финансовая грамотность, профессиональная компетенция, исследовательская компетенция, оценочные задания, дидактический потенциал

\section{Educational economic problems didactic capacity under the competence paradigm conditions}

Effective pedagogical means is required for integrated competence element formation and their maturity level evaluation under the conditions of competence paradigm in educational and professional spheres, manifested in subordination of theoretical knowledge accumulation to greater volume of professional skills and practices to perform professional work tasks. The most available means and, in some cases the only one, is the solution of practice-oriented tasks.

The aim of the article is to discuss basic approaches, conditions and practical examples of economic problems didactic capacity implementation in educational and professional spheres.

Competence approach concept as well as systemic, cognitive and personal activity approaches principles in teaching has formed the methodological basis for this work. The principles for selecting students' text books for economic problems solution are generalized in this work. The analysis of economic-based word problems of Unified National Exam in Mathematics level is presented. Personal teaching experience in making and solving problems with students is taken into account.

Basic methodological and organizational issues in educational economic problems didactic capacity implementation at different stages of competence "life cycle" are specified.

It is also demonstrated that economic type problems indisputable advantage is their ability to form not only professional cognitive and operational-technological components, but also graduate's and personality's motivation, social and behaviour model elements.

It is summed up that particular aims, determined by education level, are to be put forward for economic problems didactic capacity implementation. The necessity to increase economic problem evaluative function at entrance and final assessment stages at different education blocks or phases as well as at interdisciplinary level and in professional spheres is defined. The examples illustrating article's separate provisions can serve as guidelines for creating problem-solving and evaluation means funds formation tutorials.

Key words: competence paradigm, educational economic problem, financial literacy, professional competence, research competence, assessment tasks, didactic capacity 
компетентностной модели выпускника профессионального образования при обучении и совершенствует компетенции при их реализации на производстве согласно профессиональному стандарту. Экономические задачи влияют на мотивационную, и даже этическую, поведенческую компоненты личности.

При такой значимости экономических задач как дидактического инструмента методические аспекты их разработки и применения не в полной мере учитывают педагогический потенциал задач, не в полной мере адаптированы к требованиям «компетентностного подхода». сферы от других областей жизни общества которых проявляет себя человек. Связующим понятием является «компетенция», комплекс которых формируется в образовании, а реализуется в иных сферах уже как «компетентность» - компетенции плюс опыт работы или социальных действий человека.

Во-вторых, приоритет реальной социальноэкономической сферы, которая задает ориентиры образованию. Достаточно вспомнить, что федеральные государственные образовательные стандарты профессионального образования устанавливают требования «к результатам освоения основных образовательных программ профессионального образования в части профессиональной компетенции на основе соответствующих профессиональных стандартов» [10].

Третья особенность «компетентности» проявляется в подчинении совокупности теоретических знаний практическим умениям и навыкам. Дидактическая проблема конкретизируется до ответа на вопрос: «Какое педагогическое средство наиболее эффективно для формирования и оценки умений и навыков, сформированности компетенции?».

Доступным средством, обладающим дидактическим потенциалом как для учебного образовательного процесса профессионального и среднего образования, так и сферы труда является практико-ориентированная задача (физическая, химическая, лингвистическая, экономическая).

Неоспоримым приоритетом из этого перечня в силу социальной значимости для каждого человека обладает задача экономического типа. Действительно, вовлеченность современного человека в рыночные отношения предполагает необходимое и достаточное владение им экономической культурой, что проявляется в вынужденном умении просчитывать экономические последствия самостоятельно принимаемых решений. Так, в основе результата формирования «финансовой грамотности» [11], предполагающего сочетаемость «...знаний, умений, практических навыков ...», лежит овладение азами ситуационных экономических вычислений, что в конечном итоге должно «обеспечить финансовое благосостояние».

В то же время умение решать экономические задачи формирует профессиональную когнитивную и инструментальную составляющую

\section{Обзор литературы}

Контент-анализ массивов научной и методической информации по обсуждаемому вопросу выявил особенности структуры и содержания публикационной активности. Обсуждение методики экономической учебной задачи в работах российских педагогов активизировалось с 2015 г., когда в контрольно-измерительных материалах ЕГЭ по математике профильного уровня появился относительно «новый» вид заданий - экономическая задача. Очевидно поэтому, на настоящий момент значительную долю в совокупности научно - методических работ этой направленности составляют труды специалистов-педагогов общего и среднего образования.

Несомненным достоинством работ школьных педагогов О.Ф. Бушневой и

А.Д. Эзиевой, О.А. Пиксаевой, А.А. Прокофьева $[2 ; 13 ; 14]$ является детальная систематизация текстовых задач экономического типа, представленных в открытом банке ФИПИ, представление методически выверенные, четких алгоритмов их решений, выделение типа задач с худшим результатами ответов.

В более ранних трудах дидактической направленности Н.А.Терешина [20], И.М. Шапиро [22] и др. подчеркивается, что основная дидактическая роль школьных экономических задач состоит в мотивировании и повышения результативности изучения прежде всего математики. Однако явно прослеживается тенденция на экономическими понятиями и процессами на осознанном уровне в ущерб математическим знаниям.

Публикации, поднимающие проблему практико-ориентированных задач на уровне высшей школы представлены работами, в которых задачи по математике, реже по гуманитарным дисциплинам, рассматривают текстовое представление ситуации как способ лучшего освоения фундаментальной дисциплины. И.А. Жаравина [5], С.Ф. Митенева [7], Н.В. Никаноркина [9] с разных позиций демонстрируют мотивационную функцию экономической задачи в обучении другим предметам. Этот момент следует оценивать, как значимый, для формирования междисциплинарных связей. 
Вопросы методики экономических задач в высшей школе за редким исключением в рамках научных исследований не рассматриваются. Так, И В. Склярова вскрывает психолого-педагогические сложности при решении задач студентами заочной формы обучения, например, отсутствие индивидуализированного и своевременного пояснения решения со стороны преподавателя [16]. Работа Н.В. Вахрушевой [3] поднимает вопрос роли экономических задач при оценки компетенций бакалавра-экономиста.

При обсуждении экономических задач интерес авторов преимущественно сфокусирован на отыскании новых методов решения известных экономических задач, адаптации их к информационно-коммуникационным технологиям, а в учебных изданиях акцент делается на максимально доступном изложение основ математического аппарата для их решения.

Вопросы эволюции дидактического знания, педагогических методик и их значимости в современном образовании поднимают И.П. Смирнова [17], William E. Becker [25]. Ученый, опираясь на обзор литературы подготовленной экономистами за последние двадцать пять лет, показал, что вопросы дидактики являются и должны быть неотъемлемой частью современных педагогических дискуссий по профессиональной образовательной подготовке. Ученые, эволюционируя вместе со знанием, должны ответить на вопросы: «Чему учить?», «Как учить?» и «Как оценивать?». В одной из первой своих статей автор указывал, что лекция при подготовке бакалавров экономики несомненно важна, но необходимы инновационные и более активные формы обучения. Убедительные аргументы в пользу «тематических практических» заданий, более известных как "Case Study Teaching Method», с позиций педагога и студента приводятся в его работах [8] и трудах многих зарубежных исследователей [2628]. Так, Kevin M. Bonney отмечает, что этот прием способствует развитию критического мышления, достижению более высоких уровней когнитивного обучения по таксономии Блума, нацеливает и формирует готовность к решению более сложных экономических задач [26]. Несомненный интерес представляют работы, раскрывающие методические подходы к составлению экономических задач, трактующие элементарную формализованную экономическую задачу как Economics Short Case Study [27], а также «банки» экономических задач по предметным областям [28], которые практикуются за рубежом.

Обзор и практика педагогической деятельности выявили противоречие между дидактическим потенциалом экономических задач по формированию и оценке компетенций выпускника, личности в рыночной экономической среде, аттестации практикующего специалиста и недостаточной методической проработкой этого инструментария для достижения данной цели.
Мы предприняли попытку конкретизировать упущенные возможности использования экономических задач в образовательном процессе и представить собственное видение устранения проблем.

Результаты исследования

Каждая конкретная экономическая задача предназначена для достижения комплекса целей: педагогической, учебной, дидактической, а формулировки этих целей подсказывает модель самой задачи.

Ключевым вопросом в этом ключе является смысл, вкладываемый в понятие «экономическая задача».

Интересно наличие разных точек зрения на название этого типа задач. Для школьного уровня она определяется как «текстовая задача экономического содержания», где слово "текстовая» подчеркивает ее практическую ориентацию применительно к экономико-финансовой проблеме, через описание ситуации.

В экономическом словаре Б.А. Райзберга экономическая задача позиционируется как «задача, решаемая в процессе экономического анализа, планирования, проектирования, связанная с определением искомых неизвестных величин на основе исходных данных. В отличие от математических задач экономические задачи не всегда удается формализовать, свести только к расчету. Их решение сопровождается поиском недостающих данных, экспертными оценками, обсуждением, принятием решений» [15]. Указание на невозможность полностью формализовать экономическую задачу объясняет позицию Е.А. Третьяковой [21], использующей понятие «управленческая экономическая задача». Мы же склоняемся к тому, что учебная экономическая задача - это ситуация, разрешение которой базируется на знании математики и специфических математических моделей из области экономики, то есть базируется на использовании математических методов. Решить учебную экономическую задачу - это, прежде всего, расчетным путем отыскать верный ответ. Применение неформализуемых логических рассуждений, экспертных оценок и т.п. преобразует экономическую задачу в менеджерскую, управленческую, маркетинговую, переводя ее с уровня «Economics Short Case Study» на уровень межпредметного кейс-задания. Несомненно, это уровень высшего профессионального образования.

Наиболее значимым при решении текстовых задач экономического содержания в общем образовании школьника является предметный результат по математике - «сформированность умений применять полученные знания при решении различных задач» [12]. Отработка до «автоматизма» умений и навыков математических расчетов, применения нормативных методов 
алгебраического, арифметического, геометрического решения простейших задач (нахождение простого и сложного процента; решения неравенств, арифметической прогрессии) является основой и вузовских успехов. Многократное повторение общего метода решения для разных ситуаций обеспечивает отработку математических приемов почти до «бессознательного уровня».

Но именно эта цель - результат по математике, оказалась сдвинутой на второй план по сравнению с «экономическими знаниями». Парадокс состоит в том, что успешность математической подготовки во многом определяется формой подачи математической задачи. Школьник, владея определенными, не всегда системными знаниями в области основ экономики, «забывает» о математике, пытаясь понять суть сложной задачи, демонстрирует двойной неуспех.

На фоне общеизвестных рекомендаций по повышению результативности решения задач, полезна работа В.Ф. Спиридонова [18], который экспериментально показал существенную роль репрезентации ситуаций и ее параметров в успешности нахождения правильного ответа. Обращения к экономике состоит не только в особенности самих ситуаций, но, что немаловажно, а в их повседневном проявлении, конкретности, исключении необходимости домысливать и «представлять в воображении», что присуще физике, химии, и возможности проверки решения задачи на практике. Исследователь отмечает как достоинство сопоставимость с бытовым знанием, использование общепринятых для профессиональной сферы языковых единиц, единство терминологии, которое для школьников усложнять нет необходимости. Важнее применить типовые математические знания для ситуации по начислению банковского простого и сложного процента по вкладам и кредитам, определению стоимости акций и облигаций.

При формировании профессиональных компетенций у студента, простейшие задачи встраиваются в цепь аналогичных, основанных прежде на формализованных математических расчетах, моделируя комплексную экономическую задачу для более сложных ситуаций принятия управленческих решений. Поскольку предполагается, что фундаментальные навыки арифметических расчетов, геометрических построений и установления взаимозависимостей двух величин заложены в общей школе, то студент легче переходит с элементарного уровня к решению задач более высокого порядка.

Решение школьниками текстовых задач экономического содержания необходимо, поскольку выявляет склонность некоторых к прикладному экономическому мышлению, формирует интерес к экономике и мотивирует к осознанному выбору профессии. Следует вспомнить, что в варианты вступительных экзаменов в вузы по математике до введения ЕГЭ и в настоящее вре- мя в заданиях по вузовской программе задачи такого типа включаются обязательно, особенно если речь идет об экономических специальностях.

Но справедливо, что предметный результат по экономике для выпускника школы является вторичным (не по значимости), а по этапу его достижения - после овладения математическими расчетами.

Следует отметить, что есть задания школьной программы по содержанию и уровню сложности абсолютно идентичные вузовским экономическим задачам. Возникает вопрос: «Либо вузовская программа недогружена, либо перед школьником ставится избыточная знаниевая задача?». В последнем случае учащийся вынужден механически запоминать формулы (модели) без должной глубины осознания связи и системности применения экономических понятий. Пример таких «несвоевременных» школьных задач, взятых из материалов для подготовки к ЕГЭ, - задачи оптимизации производства товаров или услуг исходя из заданных значений и теоретического знания понятий: «операционная прибыль», «точка безубыточности», "переменные затраты», причем в объемах, значительно больших нежели арифметические задачи на проценты [23].

Использование подобного подхода к отбору задач не будет способствовать усвоению математики школьником на осознанном уровне, а у потенциального абитуриента может создать ложную иллюзию «простоты» принятия экономических решений и профессии экономиста.

С другой стороны излишне сложные, нерешенные выпускником школы задачи экономического содержания, встретившиеся в студенческой практике и вызвавшие аналогичные затруднения, могут привести к угасанию интереса к экономическим дисциплинам и профессии в целом.

В обозначенной ситуации явно прослеживается связь между одним и тем же педагогическим явлением на разных ступенях образования.

Для образовательной школы требуется чтобы в учебниках была представлена четкая методика решения экономических задач. В вузовских практических пособиях дидактическая методичность встречается не часто. И если на старших она менее востребована, в силу накопленных умений решать формализованные задачи, то на младших курсах при отработке расчетных навыков этот педагогический подход должен соблюдаться.

К числу требований по организации образовательного процесса в вузе следует отнести распределение дисциплин в учебном плане, способствующем приращению учебных умений решать задачи. Дисциплины «Микро-, и макроэкономика» или "Экономическая теория" должны изучаться параллельно с математикой или незначительно опережать математическую подготовку для применения возможностей математическо- 
го аппарата по решению задач различными способами. В курс математики обязательно должны быть введены задачи связанные с ситуациями по товарно-денежным отношениям, реализацией товаров и услуг, минимизацией расходов или максимизацией прибыли и т. п., требующие от студентов умений применять математические, алгебраические и другие действия. Такое применение задач способствует осознанному восприятию учащимися программного материала "сухой» математики. Акцентирование внимания на необходимости овладения математической теорией, под влиянием потребностей практики профессии, способствует формированию осознанных взглядов на профессиональную сферу как на область научную, что мотивирует студента бакалавра на продолжение образования в магистратуре, на занятия научной деятельностью, стимулирует к поиску нестандартных решений в практических ситуациях. Использование задач для мотивации знаний, умений, изучения методов создает условия для реализации, на этапе введения нового учебного материала, межпредметных связей. Положительным примером для формирования профессиональной и общекультурной компетенции является введение учебной дисциплины «Финансовая математика» или иной по названию, но близкий по существу. Повторение в разных формах задач, которое в нашем случае в минимальном количестве встречается не менее 3-х раз (в школе, затем в вузе при изучении математики на младших курсах и далее при изучении дисциплин профессионального блока), способствует у студентов выработке навыков принятия экономических решений до будущей профессиональной деятельности.

Интересно мнение В.Ф. Спиридонова, который характеризует экономическую задачу как двойственную. «С одной стороны, они обладают всеми чертами мыслительной задачи, с другой - обладают нормативным («культурным») способом решения, который известен заранее, что автоматически обесценивает их, превращая в нетворческие, или вообще лишает статуса задачи, сводя к материалу для отработки того или иного интеллектуального навыка» [18].

Мы же вполне допускаем и приветствуем вторую сторону для простых экономических задач, формирующую устойчивые умения - пошаговые элементы в подготовке оперативного решения задач более высокого уровня сложности. Следует учесть, что фактор быстроты принятия решения на основе расчетов в профессиональной реальной ситуации - немаловажный аргумент за овладение типовыми методиками. С позиций учебного процесса, в условиях роста числа экономических ситуаций требующих решения и выносимых в программу учебной дисциплины, при одновременном сокращении аудиторных часов для ее усвоения, доведение до разумного «автоматизма» решения простых задач, освое- ние их на математических непрофильных дисциплинах является плюсом в пользу «нормативных» способов решения. Решение типовых задач общепринятым методом может быть принято в качестве критерия оценки результатов обучения для порогового уровня, будучи соотнесенными с основным видом будущей экономической деятельности [19].

Другая сторона экономической задачи предполагает для нее статус творческого индивидуального мыслительного процесса, осуществляемого через операции синтеза, анализа и др., что обеспечивает развитие студента.

Рассматривая "решение задачи» не как результат, а как процесс его нахождения, выявляется способность экономической задачи - мотивация обучающего к научно-исследовательской деятельности.

Процесс нахождения результата предполагает, во-первых, знание и умение применить единый общий метод (подход) к нахождению результата и, во-вторых, использовать набор и последовательность действий, то есть способ решения, которым обучающийся реализует известный метод и получает искомый результат. Представляется, что творчество возможно, если принять тезис, что в рамках одного метода алгоритмы решения могут быть разными. Способ решения, будучи индивидуальным, является первой ступенькой к развитию профессиональной мыслительной деятельности, пусть на формальном математическом уровне. В этом случае положительный результат решения задачи, например, более коротким алгоритмом, или нахождение промежуточного показателя, позволяющего увидеть экономическую ситуацию в расширенном аспекте, может рассматриваться, как когнитивный процесс более высокого порядка. Однако в большинстве методических указаний к решению вузовских задач, преподаватель делает акцент не на характеристику метода, а на последовательности этапов отыскания ответа, которая с его точки зрения представляется наиболее «удачной». Такой принцип подачи пояснений к решению задачи нацеливает на запоминании алгоритма и отыскании логической связи между его этапами. Не исключая полностью такой вариант, можно рассчитывать лишь на выработку умений и навыков единственного типового решения задач. В соответствии с классификацией Г.С. Альтшуллера - это первый уровень изобретений, когда «использовано готовое решение для готовой задачи» [1]. «Ограниченность» такого подхода может быть устранена некоторыми приемами. В методических указаниях охарактеризовать только метод, не рассматривая конкретный пример, или указать, что «показан один из возможных алгоритмов расчета» и дать задание «рассчитать другим способом», если преподаватель знает, что такой путь возможен. Ход реализации метода, отличный от рекомендованного, 
можно соотнести уже с третьи уровнем изобретения (из пяти) «... изменено привычное решение» [Там же].

Приведем пример из личной практики, иллюстрирующий сказанное.

В основе решения экономической задачи по логистике «Выбор местного или территориально удаленного поставщика» лежит подход, основанный на концепции полной стоимости владения. Он подразумевает, что более низкая закупочная цена товара у удаленного поставщика по сравнению с ценой товара местного производителя не может быть единственным критерием принятия решения. Следует учитывать полную сумму издержек на транспортирование товара. Решением задачи является сравнение доли (\%) дополнительных затрат на условную единицу груза, например, $1 \mathrm{M}^{3}$, в сумме средств, выделенных на приобретение товара, с относительной разницей в цене единицы товара. В случае, если разница в цене больше доли дополнительных затрат, то товар закупаем у удаленного поставщика.

Адаптированный к практике вузовского обучения метод предлагает «классический» иными словами нормативный способ решения задачи. Он предусматривает комбинированный алгоритм решения, обязательным элементом которого является построение графика «кривой выбора поставщика». Это - функциональная за- висимость, аргументом в которой является закупочная стоимость $1 \mathrm{M}^{3}$ груза (товара) в удаленном пункте (гипотетическая, не фактическая), а функцией - отношение дополнительных затрат на доставку $1 \mathrm{~m}^{3}$ груза от удаленного поставщика на место продажи к закупочной стоимости $1 \mathrm{M}^{3}$ этого товара, \%. Способ решения - нахождение на графике точки пересечения фактической стоимости $1 \mathrm{M}^{3}$ товара и относительной разницы цен на месте и новой закупочной. Если точка попадает в область выше равновесной кривой, то товар целесообразно закупать у иногороднего поставщика, если ниже, то - нет.

Анализ вопросов и мнений, возникших у студентов в процессе решения задачи, а также результаты самостоятельного ими поиска решения без предварительной демонстрации общепринятого способа, рассматриваемого в практикумах по логистике А.М. Гаджинского [4] и других экономистов, позволил выявить не оптимальность «классического решения».

Студентами были предложены три нестандартных, не встречающиеся в известных практикумах способа нахождения результата. Это демонстрирует исследовательское начало в частной ситуации.

Первый способ усовершенствует графический вариант, делая его более наглядным и исключающем лишние предварительные расчеты (см. Табл.1, строки 1 и 2).

Таблица 1

Решение о выборе поставщика на основе расчета разницы в доле дополнительных затрат и относительной разницы цен на товар

\begin{tabular}{|c|c|c|c|c|c|}
\hline Товар & $\begin{array}{c}\text { Закупочная } \\
\text { стоимость } 1 \mathrm{M}^{3}, \\
\text { руб. }\end{array}$ & $\begin{array}{c}\text { Всего допол- } \\
\text { нительные } \\
\text { затраты, руб. }\end{array}$ & $\begin{array}{c}\text { Доля дополни- } \\
\text { тельных затрат } \\
\text { в стоимости 1м³ } \\
\text { груза, \% }\end{array}$ & $\begin{array}{c}\text { Относительная } \\
\text { разница за- } \\
\text { купочной цены } \\
\text { за единицу } \\
\text { товара, руб. }\end{array}$ & $\begin{array}{c}\text { Решение о } \\
\text { выборе постав- } \\
\text { щика }\end{array}$ \\
\hline нет & 8000 & 6272 & 78,4 & $\times$ & $\times$ \\
\hline нет & 18000 & 6862 & 38,1 & 19,1 & Местный \\
\hline А & 16000 & 6744 & 42,2 & 30,0 & Удаленный \\
\hline В & 45000 & 8455 & 18,8 & 14,3 & Местный \\
\hline С & 60000 & 9340 & 15,6 & & $\times$ \\
\hline
\end{tabular}

Предложено строить зависимость не для гипотетических значений стоимости $1 \mathrm{~m}^{3}$ товара (см. рис.1), а фактических, заданных условием (см. рис. 2).

Два других предложенных студентами способа исключают «лишние шаги» - построение кривой выбора поставщика и нахождение на ней точек, ограничиваясь табличными вариантами представления расчетных данных.

Один из «новых» вариантов предполагает расчет, а затем сравнение доли дополнительных затрат в закупочной стоимости $1 \mathrm{~m}^{3}$ товара с относительной разницей в ценах (см. табл. 1, строки 3 - 5).
Другой нестандартный способ решения предусматривает сравнение возможных физических объемов закупки товаров для двух поставщиков, исходя из известной розничной стоимости единицы товара. Результатом является наибольший объем закупки, выраженный в условных единицах груза или в натуральных единицах, свойственные товару (кг, шт.) (см. табл. 2).

Алгоритм предполагает нахождение абсолютной суммы на закупку товара у удаленного поставщика, оставшейся после вычитания дополнительных расходов.

Сравнение результатов решения задачи в студенческой группе, анализ пособий по методике 


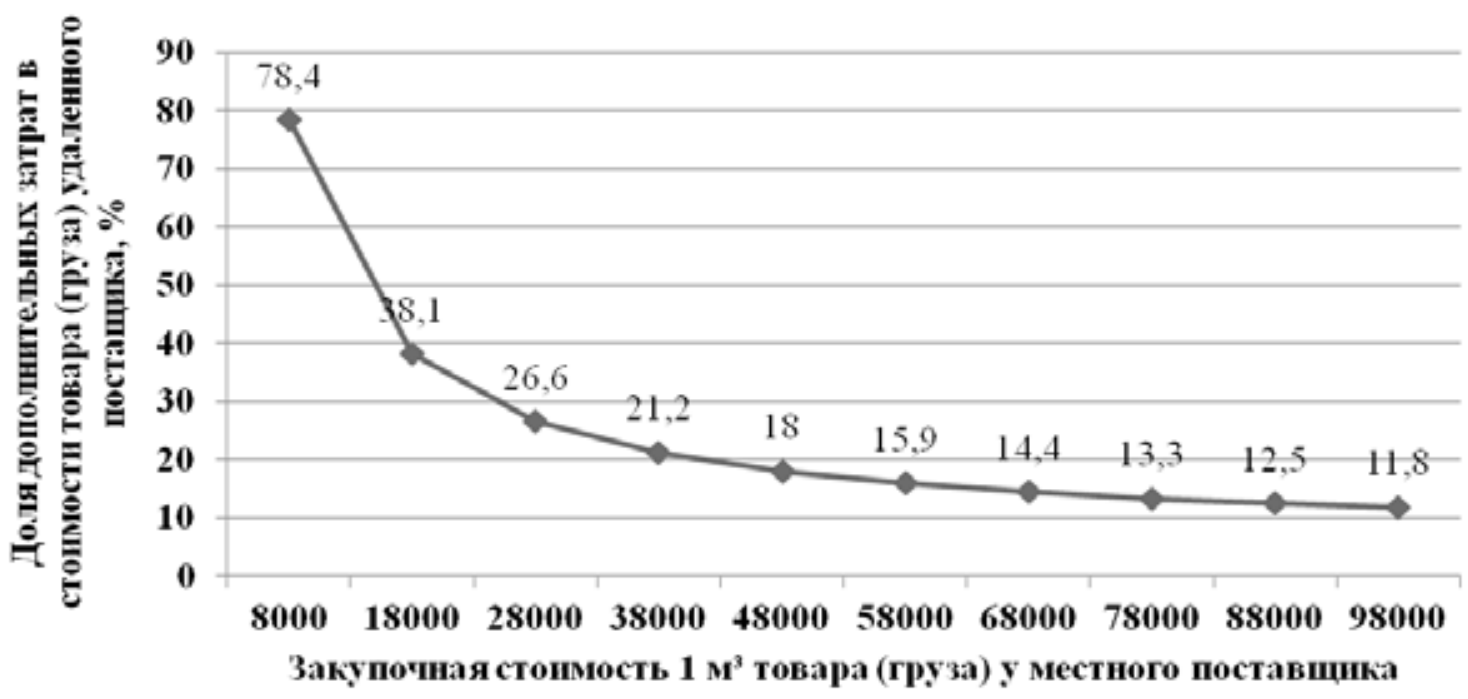

Рис. 1 Кривая выбора поставщика на основе гипотетических данных

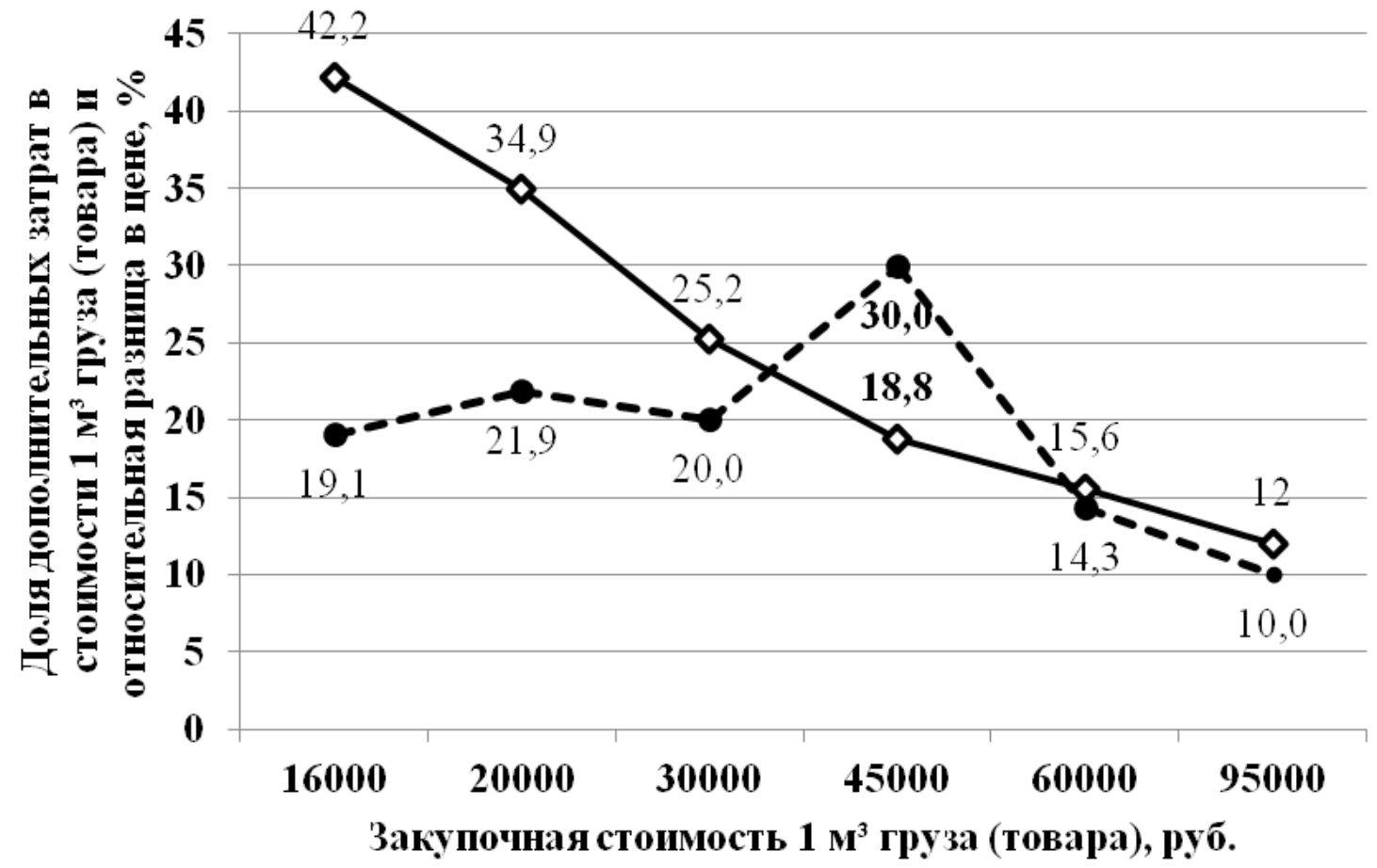

Рис.2. Кривая выбора поставщика на основе реальных данных

Таблица 2

Решение о выборе поставщика на основе расчета объемов физической закупки для местного и удаленного поставщика

\begin{tabular}{|c|c|c|c|c|c|c|c|}
\hline \multirow[b]{2}{*}{ Товар } & \multicolumn{3}{|c|}{ Местный поставщик } & \multicolumn{3}{|c|}{ Удаленный поставщик } & \multirow[b]{2}{*}{$\begin{array}{c}\text { Решение } \\
\text { о выборе } \\
\text { поставщи- } \\
\text { ка }\end{array}$} \\
\hline & $\begin{array}{c}\text { Закупочная } \\
\text { стоимость } \\
1 \text { м3 груза } \\
\text { (товара) }\end{array}$ & $\begin{array}{c}\text { Закупоч- } \\
\text { ная цена } \\
\text { за единицу } \\
\text { товара, } \\
\text { руб. }\end{array}$ & $\begin{array}{c}\text { Объем } \\
\text { закупки, } \\
\text { шт. }\end{array}$ & $\begin{array}{c}\text { Закупочная стои- } \\
\text { мость } 1 \text { м3 груза } \\
\text { (товара) с учетом } \\
\text { дополнительных } \\
\text { затрат }\end{array}$ & $\begin{array}{c}\text { Закупоч- } \\
\text { ная цена } \\
\text { за едини- } \\
\text { цу товара, } \\
\text { руб. }\end{array}$ & $\begin{array}{c}\text { Объем } \\
\text { закупки, } \\
\text { шт. }\end{array}$ & \\
\hline$A$ & 16000 & 21 & 762 & 9256 & 17 & 544 & Местный \\
\hline B & 45000 & 50 & 900 & 36544,5 & 35 & 1044 & Удаленный \\
\hline $\mathrm{C}$ & 60000 & 70 & 857 & 50658 & 60 & 844 & Местный \\
\hline
\end{tabular}


ее решения позволили выявить самими студентами повторяющуюся ошибку, приводящую к ошибочному решению: «За базовую цену принимается цена товара удаленного, а не местного поставщика, что неверно». Следовательно, есть упущения в понимании «базового экономического показателя», что нацеливает на усиление внимание при изучении соответствующей темы в курсе «Статистика». Результаты третьего варианта решения задачи актуальны не только для профиля «Коммерция», но и «Товароведение».

Анализ учебных изданий - практикумов по решению экономических задач для экономистов высшей профессиональной школы выявил три методических подхода к представлению в них экономических задач.

В основе первого лежит типизация экономических задач по методам решений, объем охвата которых нередко зависит от названия дисциплины, в рамках которой они рассматриваются.

Цель пособий этой группы, их достоинство - предоставление в распоряжение студентов экономических специальностей доступного руководства, предлагающего глубокий и полный охват всех возможных оптимизационных моделей и способов их решения на примере экономических ситуаций, то есть элементарное изложение основ математического аппарата.

Однако подобные издания были более многочисленны до перехода на программы бакалавриата. Ограниченность учебного времени на освоение подобных курсов, недостаточная математическая подготовка школьников привели к существенному сжатию их содержания, вымывания из учебного обеспечения образовательного процесса. Справедливо заметить, что они не потеряли актуальности и сегодня, например, учебное пособие Н.Н. Воробьева «Теория игр для экономистов-кибернетиков» (1985 год) необходимое для решения задач в условиях неопределенности, в которых участники рынка имеют прямо противоположные интересы, а множества их стратегий бесконечны. Признаем, что следует напрячься, чтобы понять основы, но при наличии ИКТ процесс решения отнимает минимум времени.

Наглядный пример описываемого приема типизации экономических задач приведен в работе коллектива авторов [6], систематизировавших их по видам оптимизационных моделей и методам их решения.

Несомненный плюс подобного подхода состоит в возможности преподавателей экономических дисциплин создавать банк задач не только с полным охватом по содержанию экономических проблем, но не упустить возможность включить пусть на уровне типовой - задачи с разными методами и способами их решения. Такой прием, несомненно, важен для формирования не только практических умений для прикладной сферы экономики, но и для развития исследовательской и проектной компетенций.
Второе основание типизации экономических задач, наиболее представленное и широко используемое в учебном процессе - предметная профессиональная область, частный характер экономической ситуации, требующей математического решения. Цель задач практическое закрепление теоретических знаний дисциплины. Если достоинством такого подхода является максимальный охват ситуаций в рамках темы, то учет вариантов задач с позиций применяемого математического аппарата достаточным назвать нельзя.

В таких практикумах не встретишь даже упоминания понятий «экономическая задача целочисленного линейного программирования или безусловной оптимизации». Для решения задач в ситуации взаимодействия контрагентов на рынке, которое протекает в условиях неопределенности и нередко конфликта также приводятся лишь отдельные примеры решения без ссылки на то, что в основе ее решения лежат игровые математические модели. В практикумах такой направленности обеспечивается формирование стандартных профессиональных умений и навыков, но прерывается междисциплинарная связь с ранее изученными дисциплинами, например, «Экономико-математическое моделирование и методы». Они не ориентируют студента к научно-исследовательской деятельности или ограниченно формируют компетенцию бакалавра торгового дела ОПК-2 «Способность применять методы математического анализа и моделирования, теоретического и экспериментального исследования», вынуждая вводить в учебный план дополнительную дисциплину.

Третья, самая немногочисленная группа учебных изданий объединяет подходы, отмеченные выше, соединяя 1) теоретические положения предметной области с включением главы с характеристикой математических моделей, как представлено в учебнике В.В. Глухова Менеджмент (2008 г.) или 2) ситуационные экономические задачи по видам оптимизационных моделей и моделей управления. Удачным с точки зрения дидактической организации учебного материала можно назвать учебник Г.П. Фомина «Экономико-математические методы и модели в коммерческой деятельности» (2009 г.).

Рассмотрим возможности экономических задач как средства оценивания сформированности умений и навыков.

Руководители кадровых служб предприятий, проводя аттестации специалистов с использованием тестовой технологии, сталкиваются с рядом трудностей. У большинства кадровиков сформировано устойчивое мнение, что «С помощью тестов можно оценить только знания, но невозможно оценить умения. Как тогда оценивать умения?» [8]. Но, отвечая на вопрос: «При помощи практических задач, кейсов?!», автор статьи одновременно вскрывает дидактическую 
и организационную сторону проблемы, задавая вопрос: «Насколько глубокими должны быть тесты? А кто сделает это?».

Представляется, что именно методический опыт вузовских преподавателей по разработке фонда оценочных средств для определения развития компетенций и применения педагогических измерительных материалов в рамках ФЭПО могут стать эффективным решением обозначенной проблемы для профессиональной сферы в рамках взаимного сотрудничества

Модели заданий, включающие экономические задачи определенного уровня сложности и состава (типовые, нестандартные, кейс-задания), и оценки их выполнения, реализующие классические педагогические подходы (таксономию Б. Блума, уровни достижения образовательных целей В.П. Беспалько, теорию поэтапного формирования умственных действий П.Я. Гальперина и Н.Ф. Талызиной), изначально решают образовательные цели, поставленные ФГОС ВО 3++. При соответствующей адаптации к профилю организации в сфере труда они могут использоваться при аттестации специалиста по уровню квалификации для оценки «трудовых действий», «необходимых умений и знаний», "владения навыками», предусмотренных Профессиональным стандартом, но уже по оценочной шкале, разработанной самой организацией.
Ниже представлен уровневый перечень экономически задач (тема «Складская логистика»), отвечающий дидактическим требованиям оценки уровня освоения компетенций и запросам «практиков». Правильное решение первого и второго тестовых заданий соответствует пороговому уровня развития практической составляющей компетенции; верные ответы на третье и четвертое задания соотносятся с продвинутым и высоким уровнем результатов обучения. Задания включены в Фонды оценочных средств, которые представлены в виртуальной обучающей среде MOODLE ФГБОУ ВО Красноярский ГАУ.

Тестовое задание на проверку знания методов решения задач:

Решение по выбору рационального места расположения оптового распределительного центра решается методом... (выбрать несколько вариантов ответа):

А. корреляционного анализа;

В. частичного перебора;

C. определения центра тяжести грузопотоков;

D. «дворника-стеклоочистителя»;

E. пробной точки.

Oтвет: B, C. E.

Тестовое задание на проверку понимания формализованного способа решения:

Установите соответствие между формулой и рассчитываемым показателем.

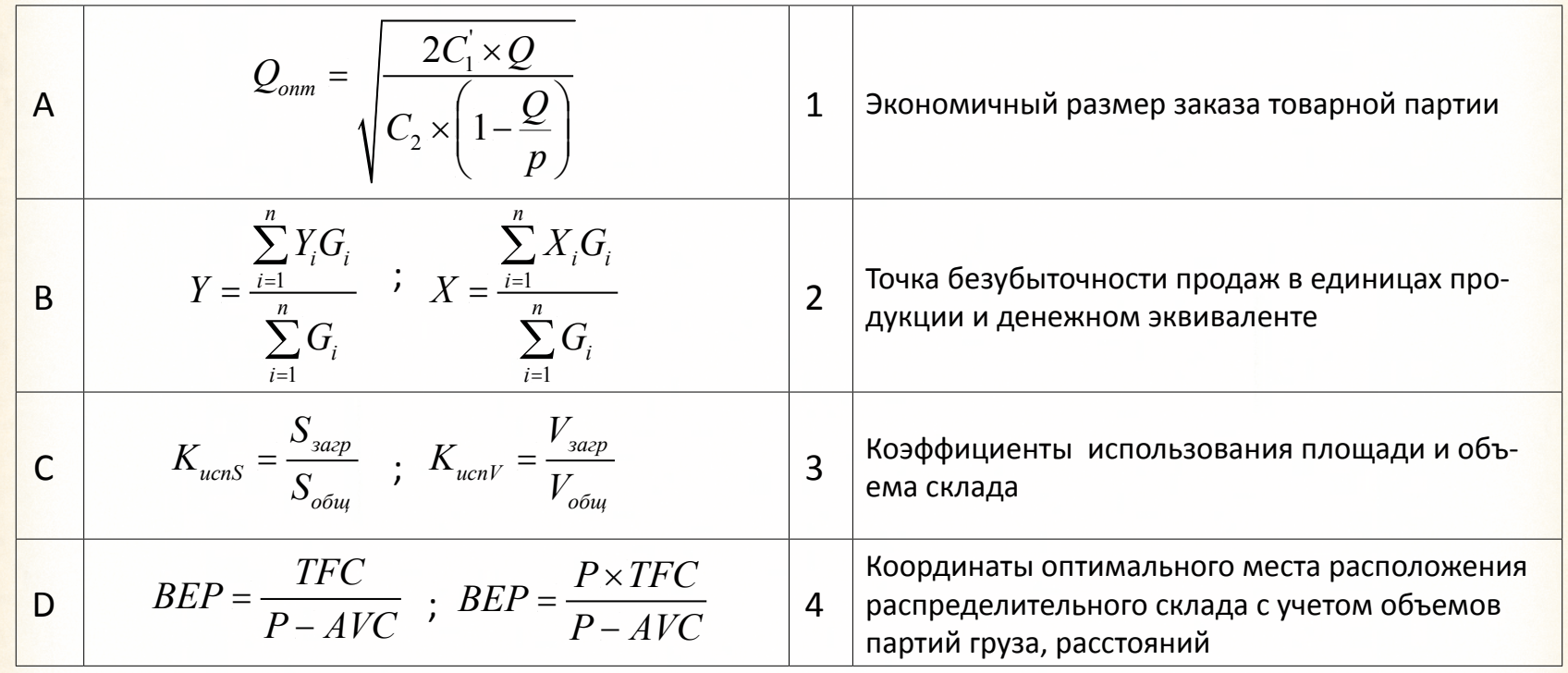

Oтвет: $A-1 ; B-4 ; C-3 ; D-2$.

Таблица 3

Тестовое задание на проверку наличие умений решать задачу:

На территории района имеется 6 розничных магазинов. Методом определения центра тяжести грузопотоков найти оптимальное место для размещения оптового распределительного склада, снабжающего магазины, если известны следующие их характеристики (см. табл. 3).

Координаты расположения магазинов в прямоугольной системе координат и месячный грузооборот

\begin{tabular}{|c|c|c|c|c|c|c|}
\hline \multirow{2}{*}{ Параметр } & \multicolumn{7}{|c|}{ Номер магазина } \\
\cline { 2 - 8 } & 1 & 2 & 3 & 4 & 5 & 6 \\
\hline$G_{i}, \mathbf{T}$ & 10 & 3 & 12 & 7 & 15 & 2 \\
\hline$X_{,}$кM & 2 & 4 & 10 & 8 & 2 & 11 \\
\hline$Y_{,}, \mathrm{kM}$ & 7 & 6 & 6 & 5 & 2 & 1 \\
\hline Oтвет: $X_{\text {склада }}=5,3 \mathrm{kM}, Y_{\text {склада }}=4,6 \mathrm{kM}$
\end{tabular}


Тестовое задание на проверку владения навыками решения задач:

На территории района имеется 3 розничных продовольственных магазина и 2 поставщика. Методом определения центра тяже- сти грузопотоков найти оптимальное место размещения оптового распределительного склада, снабжающего магазины, если известны характеристики магазинов и поставщиков (см. табл. 4).

Таблица 4

Производственные характеристики магазинов и поставщиков товаров

\begin{tabular}{|c|c|c|c|}
\hline \multicolumn{2}{|l|}{ Параметр } & \multicolumn{2}{|c|}{ Значение показателя } \\
\hline \multirow{2}{*}{ Координаты поставщиков $\left(X_{\pi \prime} Y_{n i}\right)$, км } & A & 800 & 1150 \\
\hline & Б & 50 & 650 \\
\hline \multirow{3}{*}{ Координаты магазинов $\left(X_{M j}, Y_{M j}\right)$, км } & 1 & 250 & 100 \\
\hline & 2 & 350 & 200 \\
\hline & 3 & 400 & 750 \\
\hline Транспортный тариф на перевозку груза поставщика, руб. / т×км & $Q_{\Pi}$ & 30 & \\
\hline Транспортный тариф на перевозку груза магазина, руб. / т×км & $Q_{M}$ & 32 & \\
\hline \multirow{2}{*}{ Объемы перевозок ј-го поставщика, т } & $Q_{\Pi A}$ & 1150 & \\
\hline & $Q_{\Pi 5}$ & 650 & \\
\hline \multirow{3}{*}{ Объемы перевозок ј-го магазина, т } & $Q_{M 1}$ & 100 & \\
\hline & $Q_{M 2}$ & 200 & \\
\hline & $Q_{M 3}$ & 750 & \\
\hline
\end{tabular}

Oтвет: $X_{\text {склада }}=470,5 \mathrm{kM}, Y_{\text {склада }}=821,3 \mathrm{kM}$

Организационными и психолого-педагоги-

Заключение

В результате проведенного теоретического и экспериментального исследования можно сделать ряд обобщений.

Дидактический потенциал экономических задач определяется их возможностью реализовать комплекс взаимосвязанных образовательных социальных и личностно-ориентированных целей. В их числе: обучение математике и специальным экономическим знаниям на уровне практических умений и навыков, развитие исследовательского начала и критического мышления, немаловажного при принятии экономически обоснованного управленческого решения, формирование экономической культуры и финансовой грамотности. Аксиоматична роль экономических задач для объективного оценивания учебных достижений и соответствия профессиональной компетентности специалиста занимаемой им должности в трудовых организациях. ческими условиями эффективной реализации дидактического потенциала исследуемого феномена в контексте компетентностной парадигмы выступает дидактически обоснованный и методически подкрепленный банк экономических задач для каждой ступени образования, дисциплины, этапа их применения и т.п.

Развитие потенциала экономических задач как наращивание и совершенствование их способности выполнять образовательные функции возможны в разных направлениях. Актуальными на настоящий момент являются: «экономизация" дисциплин или направлений подготовки в контексте эколого-преобразовательной деятельности человека; необходимость адаптации к социальной сфере математического и гуманитарного образования. Затраты времени и иных усилий преподавательского корпуса окупятся высоким уровнем профессионально-личностного развития выпускника.

ЛИТЕРАТУРА

1. Альтшуллер Г.С., Верткин И.М. Как стать гением: жизненная стратегия творческой личности. Минск: Беларусь, 1994. 479 с

2. Бушнева О.Ф., Эзиева А.Д. Анализ задач экономического содержания из открытого банка заданий ЕГЭ 2017 года // Вестник Таганрогского института имени А.П. Чехова. 2017. № 1. С. 184-190.

3. Вахрушева Н.В. Прикладные задачи математики как инструмент оценки компетенций бакалавров направления подготовки «Экономика» // Теоретические и прикладные аспекты современной науки. 2015. № 7-9. С. 29-33.

4. Гаджинский А.М. Практикум по логистике. М.: Издательско-торговая корпорация «Дашков и К^, 2012.312 с.

5. Жаравина И.А. Использование ситуационных задач в адаптации учебного материала гуманитарных дисциплин при обучении студентов технического вуза по заочной форме // Фундаментальные исследования. 
2014. № 8-4. С. 955-960.

6. Методы оптимизации в экономике: Методические указания к курсовым работам / Т.Б. Волкова [и др.]. М.: Изд. МАИ, 1994. 52 с.

7. Митенева С.Ф. Формирование творческих способностей обучающихся при изучении математики // Среднее профессиональное образование. 2010. № 5. С. 14-15.

8. Митрофанова В.В. Профессиональные стандарты в вопросах и ответах // Секретарь-референт. 2015. № 4. С. 39-44.

9. Никаноркина Н.В. Профессионально ориентированные задачи как средство осуществления профессионально направленного обучения математике студентов экономических вузов // Молодой ученый. 2014. № 13. С. 276-279.

10. Об образовании в Российской Федерации: федер. закон Рос. Федерации от 29.12.2012 № 273-Ф3. URL: http://base.garant.ru/70291362 / (дата обращения: 18.02.2018).

11. Об утверждении Стратегии повышения финансовой грамотности в Российской Федерации на 2017 - 2023 гг.: распоряжение Правительства Рос. Федерации от 25.09.2017 г. № 2039-p. URL: http://www.garant.ru/products/ ipo/prime/doc/71675558/ (дата обращения 18.02. 2018).

12. Об утверждении федерального государственного образовательного стандарта среднего (полного) общего образования: приказ Министерства образования и науки Рос. Федерации от 17.05.2012 г. № 413. URL: http:// base.garant.ru/70188902/ (дата обращения: 18.04. 2018).

13. Пиксаева О.А. Педагогический эксперимент по введению элективного курса «Задачи с экономическим содержанием», как средство улучшения подготовки старшеклассников к ЕГЭ // Актуальные проблемы развития среднего и высшего образования: межвуз. сб. науч. тр. / Челябинск. 2017. 180 с.

14. Прокофьев А.А. Рекомендации по подготовке к выполнению финансово-экономических задач ЕГэ повышенного уровня. URL: http://math-conf.msu.ru/netcat_files/userfiles/conf_2017.pdf (дата обращения: 10.05. 2018).

15. Райзберг Б.А., Лозовский Л.Ш., Стародубцева Е.Б. Современный экономический словарь: 10000 терминов. М.: Инфра-М, 1996. 496 с.

16. Склярова И. В. Проблемы формирования умений решать математические текстовые задачи у студентов дистанционного обучения // Университетские чтения - 2017: материалы науч.-методических чтений ПГУ, 12-13 января 2017 / Пятигорск. 2017. С. 53-56.

17. Смирнов И.П. Дидактика: Развитие или застой? // Образование и наука. 2016. № 1. С. $133-144$.

18. Спиридонов В.Ф. Психологические механизмы решения текстовых задач по математике. URL: https://psy.su/ feed/4064/ (дата обращения: 18.04.2018).

19. Стефанова Г.П., Крутова И.А. Байгушева И.А. Типовые профессиональные задачи как целевой ориентир подготовки бакалавров и магистров в условиях реализации ФГОС ВО // Известия ВГПУ. 2017. № 3 (116). С. 53-58.

20. Терешин Н.А. Прикладная направленность школьного курса математики: Книга для учителя. М.: Просвещение, 1996. 96 с.

21. Третьякова Е.А. Управленческая экономика: учебник и практикум для бакалавриата и магистратуры. М.: Юрайт. 2018. 329 с.

22. Шапиро М.И. Мотивационная функция задач в обучении математики. URL: https://www.altspu.ru/Journal/ pedagog/pedagog_4/articl_12.html (дата обращения: 30.04.2018).

23. Шестаков С.А. ЕГЭ 2017. Математика. Задачи с экономическим содержанием. Задача 17 (профильный уровень) / Под ред. И.В. ЯщенкоМ.: МЦНМО, 2017. 208 с.

24. Becker William E. Teaching tools: Teaching methods in undergraduate economics // Economic inquiray.1995. Volume33. № 4. P. 692-700.

25. Becker William E. Teaching Economics in the 21st Century // The Journal of Economic Perspectives. 2000. Vol. 14. No. 1. P. 109-119.

26. Kevin M. Bonney. Case Study Teaching Method Improves Student Performance and Perceptions of Learning Gains // Journal of microbiology \& biology education. 2015. May. № 16 (1). P. 21-28.

27. Case-study // [Internet resource]. URL: http://www.pressacademia.org/case-studies (accessed: 10 May 2018).

28. Economics Case Studies // [Internet resource]. URL: http:// http://www.icmrindia.org/casestudies/Case_Studies. asp?cat=Economics (accessed 10 May 2018).

\section{REFERENCES}

1. Altshuller G.S., Vertkin I.M. How to become the genius: vital strategy of the creative person. Minsk, Belarus Publ., 1994. 479 p. (in Russian)

2. Bushneva O.F., Eziyeva A.D. The analysis of problems of economic contents from open bank of the USE tasks of 2017. Bulletin of the Taganrog institute of A.P. Chekhov. 2017. 1. pp.184-190. (in Russian)

3. Vakhrusheva N.V. Applied problems of mathematics as tool of assessment of competences of bachelors of the direction of preparation «Economy». Theoretical and applied aspects of modern science. 2015. no. 7-9. pp. 29-33. (in Russian)

4. Gadzhinsky A.M. Workshop on logistics. Moscow, Publishing and trade corporation «Dashkov and Co», 2012.312 p. (in Russian)

5. Zharavina I.A. Use of situational tasks in adaptation of a training material of humanitarian disciplines when training students of technical college in the correspondence form. Basic researches. 2014. no. 8-4. pp. 955-960. (in Russian)

6. Optimization methods in economy: Methodical instructions to term papers. T.B. Volkova [etc.]. Moscow, MAI Press Publ., 1994. 52 p. (in Russian)

7. Miteneva S.F. Formation of creative abilities of students when studying mathematics. Secondary professional education. 2010. no. 5. pp. 14-15. (in Russian)

8. Mitrofanova V.V. Professional standards in questions and answers. Administrative assistant. 2015. no. 4. pp. 39-44. (in Russian)

9. Nikanorkina N.V. Professionally focused tasks as means of implementation of professionally directed training in 
mathematics of students of economic higher education institutions. Young scientist. 2014. no. 13. pp. 276-279. (in Russian)

10. About education in the Russian Federation: federal law Rus. Federation from 12/29/2012 № 273-FL. Available at: http://base.garant.ru/70291362/ (accessed: 11 August 2018).

11. About the adoption of Strategy of increase in financial literacy in the Russian Federation for 2017 - 2023: order of the Government of the Rus. Federation from 9/25/2017 № 2039-o. Available at: https://www. garant.ru/products/ ipo/prime/doc/71675558 / (accessed: 18 November 2017).

12. About the approval of the federal state educational standard of the secondary (full) general education: order of the Ministry of Education and Science of the Russian Federation from 5/17/2012 № 413. Available at: http://base. garant.ru/70188902/ (accessed: 18 April 2018).

13. Piksayeva O.A. A pedagogical experiment on introduction of the elective course "Tasks with Economic Contents», as means of improvement of training of seniors for the USE // Current problems of development of secondary and higher education: interhigher education institution: col. of scien. works. Chelyabinsk. 2017. 180 p. (in Russian)

14. Prokofiev A.A. Recommendations about preparation for performance of financial and economic problems of the USE of the increased level. Available at: http://math-conf.msu.ru/netcat_files/userfiles/conf_2017.pdf 2017 (accessed: 10.05.2017). (in Russian)

15. Rayzberg B.A., Lozovsky L.Sh., Starodubtsev E.B. Modern economic dictionary: 10000 terms. Moscow, Infra-M Publ., 1996. 496 p. (in Russian)

16. Sklyarova I.V. Problems of formation of abilities to solve mathematical text problems at students of distance learning // University readings - 2017: materials of scientific and methodical readings PSU, on January 12-13, 2017. Pyatigorsk: Publishing house Pyatigorsk state university, 2017. pp. 53-56. (in Russian)

17. Smirnov I.P. Didactics: development or stagnation? The Education and science journal. 2016. no. 1. pp. 133-144. (in Russian)

18. Spiridonov V. F. Psychological mechanisms of solving text problems in mathematics. Available at: https://psy.su/ feed/4064/ (accessed: 18. April 2018). (in Russian)

19. Stefanova G.P., Krutova I.A., Baygusheva I.A. Standard professional tasks as a target reference point of training of bachelors and masters in the conditions of realization of FSOS HE. Bulletin of the Voronezh State Pedagogical University. 2017. no. 3 (116). pp. 53-58. (in Russian)

20. Tereshin N.A. Applied orientation of a school course of mathematics: The book for the teacher. Moscow, Education Publ., 1996. 96 p. (in Russian)

21. Tretyakova E.A. Administrative economy: the textbook and a practical work for a bachelor degree and a magistracy. Moscow, Yurayt publishing house. 2018. 329 p. (in Russian)

22. Shapiro M.I. Motivational function of tasks in training of mathematics. Available at: https://www.altspu.ru/Journal/ pedagog/ (accessed 30 April 2018).

23. Shestakov S.A. USE of 2017. Mathematics. Tasks with economic contents. Moscow, MCSMA Publ., 2017. 208 p. (in Russian)

24. Becker William E. Teaching tools: Teaching methods in undergraduate economics. Economic inquiray, 1995. Vol. 33, no. 4. pp. 692-700.

25. Becker William E. Teaching Economics in the 21st Century. The Journal of Economic Perspectives. 2000. Vol. 14 (1). pp. 109-119.

26. Kevin M. Bonney. Case Study Teaching Method Improves Student Performance and Perceptions of Learning Gains. Journal of microbiology \& biology education, 2015. May. no. 16 (1), pp. 21-28.

27. Case-study // [Internet resource]. Available at: http://www.pressacademia.org/case-studies (accessed 10 May 2018).

28. Economics Case Studies // [Internet resource]. Available at: http:// http://www.icmrindia.org/casestudies/Case_ Studies.asp?cat=Economics (accessed 10 May 2018).

\section{Информация об авторе \\ Васильева Наталья Олеговна \\ (Россия, Красноярск)}

Кандидат технических наук, доцент кафедры

организации и экономики сельскохозяйственного производства

Красноярский государственный аграрный университет

E-mail: natasha.krasnoyarsk@gmail.com

\section{Information about the author}

Natalya O. Vasileva

(Russia, Krasnoyarsk)

PhD in Technical Sciences

Associate Professor at the Department of the organization and economics agricultural production

Krasnoyarsk State Agrarian University

E-mail: natasha.krasnoyarsk@gmail.com

\section{Ссылка для цитированиягост}

Васильева Н. О. Дидактический потенциал учебных экономических задач в условиях компетентностной парадигмы // Перспективы науки и образования. 2018. № 5 (35). C. 82-93. doi: 10.32744/pse.2018.5.9
For Reference ${ }^{\text {APA }}$

Vasileva, N. O. (2018). Educational economic problems didactic capacity under the competence paradigm conditions. Perspektivy nauki i obrazovania-

Perspectives of Science and Education, 35 (5), 82-93. doi: 10.32744/pse.2018.5.9. (In Russ., abstr. in Engl.) 